\title{
ENSINO-APRENDIZAGEM: REFERENCIAÇÃO E PROGRESSÃO TEXTUAL NO ENSINO SUPERIOR
}

\author{
TEACHING-LEARNING: REFERENCE AND TEXTUAL \\ PROGRESSION IN HIGHER EDUCATION
}

\author{
Antonia Alves Pereira* \\ Ingedore Villaça Koch
}

\section{RESUMO}

Neste artigo, discutimos referenciação e progressão textual nas produções escritas de alunos do PARFOR-Letras, Língua Portuguesa. Nossa pesquisa revelou que esses alunos apresentavam dificuldades para fazer um texto progredir, além de dificuldades no processo de referenciação. No decorrer desse artigo, trabalhamos com a hipótese de que essas dificuldades são provenientes do tipo de ensino de língua a que estiveram expostos e sugerimos estratégias que podem ser úteis ao ensino de referenciação e progressão textual. Palavras-chave: ensino-aprendizagem; referenciação; progressão textual

\section{ABSTRACT}

This article discusses reference and textual progression in the written production of students in the PARFOR-Letras, Portuguese language. It was found that these students have difficulty in making their texts progress, as well as difficulties in the process of reference. We base our discussion on the hypothesis that these difficulties stem from the type of language teaching to which they were exposed. Useful strategies are suggested for the teaching of reference and textual progression.

Keywords: teaching-learning; reference; textual progression

\section{INTRODUÇÃO}

A década 1997 a 2007 foi considerada a da Educação. Em 1998, com a publicação dos Parâmetros Curriculares Nacionais (PCNs), o Ministério da Educação (MEC) tentou dar um novo rumo ao ensino no país. Aqui, interessa-nos, especificamente, o ensino de língua materna.

É parte comum nos PCNs: o objetivo maior do ensino de língua Portuguesa deve ser o ensino da leitura e da escrita:

\footnotetext{
* UFPA, Belém (PA). Brasili antoniapereira1@yahoo.com.br; UNICAMP, Campinas (SP). Brasili ingedore@gmail.com
} 
O eixo dessa discussão no ensino fundamental centra-se, principalmente, no domínio da leitura e da escrita pelos alunos, responsável pelo fracasso escolar que se expressa com clareza nos dois funis em que se concentra a maior parte da repetência: na primeira série (ou nas duas primeiras) e na quinta série. No primeiro, pela dificuldade de alfabetizar; no segundo, por não se conseguir levar os alunos ao uso apropriado de padrões da linguagem escrita, condição primordial para que continuem a progredir (BRASIL, PCN, Vol. 2, 1998, p. 17).

Este trabalho tem como objetivo discutir aspectos da referenciação e progressão textual em produções de alunos do PARFOR-Letras, Língua Portuguesa ${ }^{1}$ A nossa pesquisa partiu da hipótese, com base em dados preliminares ${ }^{2}$, de que os alunos desse programa tinham dificuldades para produzir textos de natureza acadêmica. Percebíamos, muitas vezes, que o texto prosseguia em círculos, outras vezes era difícil encontrar a base de onde partiam certas ideias, como um barco à deriva que sabe que precisa chegar a algum lugar, mas não sabe onde se encontra e nem para onde está indo. Os textos - cujos autores demonstravam dificuldades extremas para ancorar uma informação e para prosseguir com essa informação, acrescentando informações novas - eram mais frequentes do que deveriam ser para o nível em que esses professores/alunos se encontravam.

Parece estranha uma hipótese como essa, quando se trata de profissionais de Língua Portuguesa. Entretanto, não o será se verificarmos que são provenientes de práticas docentes pautadas no ensino de língua nos moldes da gramática tradicional, que parte da concepção de língua enquanto sistema, em que o ensino da nomenclatura gramatical é o privilegiado em detrimento do ensino da leitura e da escrita. Trata-se de reflexos de práticas educativas e curriculares do Ensino Médio que têm sido alvo de constantes debates sobre o ensino da língua materna, da leitura e da escrita, adicionadas a questões da escola pública brasileira.

Encontramos pensamento análogo em Matêncio (2006, p. 95). Ao se referir aos alunos do curso de Letras, a autora faz a colocação seguinte:

\begin{abstract}
Afinal, quando ingressam no curso, muitos alunos trazem consigo representações do senso comum, segundo as quais "não sabem falar português", "não sabem escrever", "língua é norma padrão", "aprender português é aprender gramática" (as quais, infelizmente, a escola, muitas vezes corrobora).
\end{abstract}

Fatores como esses corroboram a hipótese desse trabalho.

1 Os alunos do PARFOR a que fazemos referência aqui são parte de um grupo de alunos da Universidade Federal do Pará e todos concluíram a Educação Básica em escolas públicas. Os textos analisados foram coletados durante o primeiro ano de graduação desses alunos.

2 Os dados preliminares foram provenientes de nossas observações das produções escritas desses alunos durante a disciplina Fundamentos da Linguística, ministrada por nós. 
Partindo do pressuposto de que a referenciação e a progressão textual são os pontos de partida na produção textual, resolvemos começar nossas investigações por esses dois aspectos.

Adotamos dois pressupostos gerais. Um deles diz respeito à referenciação como atividade discursiva, discutido em autores como: Koch \& Elias $(2010,2009)$; Koch $(2006,2002,1997)$, Koch \& Marcuschi (1998); Marcushi $(2008,2001)$; Cavalcante (2003); Apothéloz e Reichler-Beguelin (1995); Apothéloz (2003); Mondada (1994) e Mondada \& Dubois (1995) e tudo aquilo que provém de assumir a referenciação como atividade discursiva, tais como a língua entendida numa concepção sociocognitivo-interacional e o texto como lugar de interação. E o segundo pressuposto é fundamentado na ideia de que a leitura e a produção textual são essenciais ao ensino/aprendizagem, portanto ponto de partida e verdadeiro fundamento de uma educação que se quer eficiente. Essas ideias são discutidas, entre outros, nos PCNs, em Possenti (1996) e em Geraldi (1999).

Dividimos este artigo da seguinte forma: no primeiro momento, discutimos a noção de texto dentro da escola pública brasileira. Na sequência, discutimos os dados e, por fim, estratégias de ensino, que poderão auxiliar a produção textual de alunos universitários que apresentem dificuldades como as que serão apresentadas aqui.

\section{ASPECTOS DA ESCOLA BRASILEIRA E A NOÇÃO DE TEXTO}

\subsection{Aspectos da escola brasileira}

É de nosso conhecimento que o ensino na Educação Básica, até meados da década de 90, era pautado no ensino de gramática, esta como sinônimo de um conjunto de nomenclaturas que os alunos deviam decorar para aplicá-lo nas provas, a fim de obter promoção para as séries seguintes. Para agravar a situação, o material que sustentava as ilustrações dessa gramática provinha de textos de escritores consagrados na Literatura, principalmente, escritores como Machado de Assis. É necessário, de fato, que a escola parta de escritores clássicos, porém, não se limite a eles, uma vez que a modalidade escrita não é a única variedade da língua e, além disso, a língua está sujeita à historicidade, isto é, ela é passível de mudança no tempo e no espaço, exatamente por ser dinâmica assim como o é a sociedade. Dessa forma, voltar o ensino para esse tipo de atividade é torná-lo pouco produtivo do ponto de vista da funcionalidade social da língua.

Conforme Antunes (2010, p. 32): 
Uma gramática voltada para a nomenclatura e a classificação das unidades; portanto uma gramática dos "nomes" das unidades, das classes e subclasses dessas unidades (e não das regras de seu uso) (...) pode desenvolver nos alunos (...) apenas a capacidade de "reconhecer" as unidades e de nomeá-las corretamente.

Com isso, vemos que os alunos, expostos a um tipo de ensino como esse, desenvolverão a capacidade de análise de nomenclaturas, pois foi isso que a escola ensinou.

As atividades de leitura e compreensão de textos eram mecânicas. Na maioria das vezes, consistiam em decorar pedaços de uma lição para ler na mesa do professor ou responder a perguntas de um texto, que de interpretação nada tinham, apenas reprodução do conteúdo, isto é, as questões de interpretação não iam além de decodificação do texto e reprodução de partes desse texto nas respostas. O conteúdo dessas 'leituras' era desvinculado das práticas sociais, consequentemente, desvinculado de usos reais, em situações de comunicação autênticas, estando, pois em desacordo com o que apregoam os PCNs.

Conforme Antunes (2010, p. 25), ainda se pode constatar em torno da escrita:

A prática de uma leitura mecânica e periférica, centrada, inicialmente, nas habilidades motoras de produzir sinais gráficos e, mais adiante, na memorização pura e simples de regras ortográficas: para muita gente, não saber escrever ainda equivale a escrever com erros de ortografia.

Percebe-se, assim, uma proposta de ensino de cunho behaviorista em que se aprende mediante a repetição, e o conhecimento é algo adquirido e não construído nas práticas sociais.

Esse tipo de ensino parte da concepção de língua como código, instrumento de comunicação e de sujeito como determinado pelo sistema. Conforme Koch (2002, p. 16) em concepções de língua como esta:

O texto é visto como simples produto da codificação de um emissor a ser decodificado pelo leitor/ouvinte, bastando a este, para tanto, o conhecimento do código, já que o texto, uma vez codificado, é totalmente explícito. Também nesta concepção o papel do decodificador é essencialmente passivo

Percebemos que uma prática educativa pautada em modelos de leitura e de escrita, como os apresentados anteriormente, mostra-se deficitária. Precisou-se, pois, da intervenção do MEC, conforme vimos anteriormente, baseado em anos de pesquisa de renomeados profissionais como Koch (1992), Kleiman (1989, 1993, 1995), Soares $(1986,1996)$, Teberosky (1994) Teberosky \& Cardoso (1989) e Rojo 
$(1989,1996)$ para se assegurar o espaço da leitura e da escrita na Educação Básica, partindo do pressuposto de que o ato de bem escrever passa pelo ato de ler.

Foi partindo de constatações como essa e de uma análise prévia de textos de alunos do PARFOR, que levantamos hipóteses sobre suas dificuldades de escrever textos de gênero acadêmico, conforme dito anteriormente.

Ressaltamos, aqui, que houve tentativas significativas de mudanças para o ensino nas décadas de 1960 e 1970, entretanto a preocupação primeira era como ensinar e não o que ensinar. Até então, prevalecia na educação a tese behaviorista, que defendia a ideia de que se aprendia mediante a repetição. Tinha-se nessa concepção um sujeito passivo, que recebia informações e, através do condicionamento, memorizava-as. Com o aparecimento das teses Construtivistas de Piaget e Sociointeracionista de Vygotsky, passou-se a questionar a tese behaviorista e a defender a ideia de que o sujeito passa por diversas fases de maturação e que estas fases estão diretamente relacionadas ao nível de aprendizado para o qual está preparado o indivíduo; ou seja, para que a aprendizagem se dê de forma efetiva, o organismo do individuo precisa estar pronto/maduro. Segundo Piaget, uma criança poderia até aprender algo que deveria ser aprendido no seu próximo estágio de desenvolvimento, mas isso demandaria um esforço muito maior do que se estivesse no estágio adequado àquele tipo de aprendizado. Vygotsky defendia que o ser aprende largamente na interação com o outro e defendia que na escola o professor era o mediador entre o saber e o aluno. Portanto, este era visto como um sujeito ativo, senhor de seu aprendizado, mas precisava do outro para chegar a um ponto que ainda não conseguia alcançar sozinho - foi isso o que chamou de Zona de Desenvolvimento Proximal (ZDP).

Vale dizer que foram teorias, cuja influência na maneira de ensinar é preponderante até hoje, mas que não influenciaram significativamente quais conteúdos ensinar, especialmente, por se tratar de teorias que versam sobre o ensino na sua totalidade. Partia-se de ideias de que o domínio de técnicas de ensino garantiria o sucesso escolar.

Sabe-se que, a partir de uma descoberta na ciência até sua aplicação na sociedade, passam-se anos. Assim aconteceu com as teorias linguísticas no que se refere ao ensino de língua e assim foi com os PCNs.

Ao final da década de 1960 e início de 1970 em diante, apareceram novos ramos da linguística como a Sociolinguística, a Analise do Discurso, a Linguística Textual, a Semântica e a Pragmática, bem como a Linguística Aplicada (desmembrando-se da Linguística), que ofereciam múltiplos olhares sobre a linguagem e seu ensino, olhares que iam desde a língua em seu contexto sociocultural até sua 
aplicação em sala de aula. A partir desse momento, passaram-se décadas para que o MEC as adotasse como orientação para o ensino de língua.

Quando os PCNs foram publicados, encontraram professores que tinham recebido formações diferentes daquelas que os orientavam até então, portanto, profissionais que, certamente, enfrentariam grandes dificuldades para ministrar um novo ensino numa roupagem diferente daquela que trajaram e os prepararam para o mercado de trabalho. É bom não deixarmos de lembrar de que grande parte dos professores, principalmente das regiões Norte e Nordeste, ainda não possuíam nível superior quando foram ensinar em sala de aula. Durante aulas e curso de formação de professores é comum se ouvir relatos de que ficaram sem saber o que fazer, estavam acostumados a ensinar gramática, aprenderam o que era substantivo, adjetivo, advérbio etc.. e isso era o que ensinavam. Com essa nova perspectiva de ensino, ensinariam o quê, já que não tinham recebido esse conhecimento que exigia o MEC? É certo que o Ministério da Educação se preocupou em oferecer cursos de formação de professor, mas isso não foi suficiente para sanar o problema, pelo menos no seu momento inicial. E isso se deu de forma tão intensa que, a partir de 1998, houve uma verdadeira proliferação de cursos de graduação, culminando hoje com esse grande programa de formação de professores, chamado PARFOR. Portanto, o MEC mostra-se preocupado com a formação de seus professores.

Rojo (2005, p. 11) faz a seguinte constatação:

Em todo o período de discussão que acabei de relatar, as propostas e experiências de implementação dos PCNs diziam respeito, essencialmente, a duas frentes: a formação de professores para a implementação de propostas de ensino e as práticas didáticas e projetos escolares levados a efeito em sala de aula. Cabe também ressaltar que, na discussão das práticas didáticas de sala de aula, formatadas em projetos de ensino-aprendizagem de gêneros, não por acaso, privilegiou-se sempre gêneros argumentativos, um dos domínios da linguagem fortemente enfatizados nos PCNs e grandemente ausente das práticas correntes de sala de aula.

Portanto, quase uma década depois da publicação dos PCNs, ainda são encontradas práticas docentes que não preparam seus alunos para o enfrentamento ou continuação (adequada) de seus estudos (sem grandes entraves), pois os textos de natureza argumentativa são de suma importância, tanto na vida acadêmica como profissional de todos nós, do que decorre a importância que é dada a esse gênero pelos PCNs.

A maioria dos alunos do PARFOR, de cujo corpus se vale este trabalho, foi fruto de uma formação baseada no ensino de gramática. Logo, é de se compreender que sua produção textual ainda esteja aquém da desejada para o nível em que se encontram. Além disso, há um fator que não se pode deixar de levar em consideração: 
a maioria dos alunos/professores que participam desta pesquisa reside na zona rural, o que dificulta ainda mais sua formação.

\subsection{Texto, escola e contexto de produção}

De acordo com Koch (2002), a concepção de texto depende das concepções que se tenha de língua e de sujeito. Como vimos anteriormente, a noção de texto que preponderava no ensino era a que correspondia à de língua como sistema e à de sujeito passivo, isto é, texto como "simples produto da decodificação de um emissor a ser decodificado pelo leitor/ouvinte, bastando a este, para tanto, conhecimento do código, já que o texto, uma vez codificado, é totalmente explícito" (op. cit., p. 16).

Os estudos de Van Dijk \& Kintsch (1983) dão um grande impulso à abordagem cognitiva do texto, que vai se fortalecendo, ao longo do tempo. Novas pesquisas experimentaram e discutiram novos olhares sobre o texto até se chegar à abordagem sócio- cognitiva.

Em Bakhtin (1986, p. 123), já se encontra um pensamento bem formado sobre a importância do fenômeno social nas produções verbais:

A verdadeira substância da língua não é constituída por um sistema abstrato de formas linguísticas nem pela enunciação monológica isolada, nem pelo ato psicofisiológico de sua produção, mas pelo fenômeno social da interação verbal, realizada através da enunciação ou das enunciações. A interação verbal constitui assim a realidade fundamental da língua.

A noção de texto hoje adotada na Linguística Textual é pautada numa concepção sociocognitivo-interacional de língua, segundo a qual o discurso é o lugar de interação onde os sujeitos se constroem e são construídos ao longo de todo processo de interação (Koch, 2005). Conforme Koch \& Elias (2010, p. 34), o lugar de interação é o texto, onde os sentidos são construídos e reconstruídos com base em pistas textuais deixadas por seu autor e com base nos conhecimentos prévios do leitor. Ainda conforme essas autoras:

\footnotetext{
A escrita não é compreendida em relação apenas à apropriação das regras da língua, nem tampouco ao pensamento e intenções do escritor, mas, sim, em relação à interação escritor-leitor, levando em conta, é verdade, as intenções daquele que faz uso da língua para atingir seu intento sem, contudo, ignorar que o leitor com seus conhecimentos é parte constitutiva desse processo.
}

Para Beaugrande (1997, p. 10): "É essencial que se veja o texto como um evento comunicativo em que convergem ações linguísticas, sociais e comunicativas 
e não simplesmente como a sequência de palavras escritas ou faladas". Assim, vemos que a constituição de um texto está além do cotexto de produção, levando em consideração também o contexto e os atores/interlocutores envolvidos.

Além disso, houve a constatação de que o sentido é conditio sine qua non para a existência de um texto. Conforme Koch (2002, p. 17):

O sentido de um texto é [...] construído na interação texto sujeito (ou texto-co-enunciadores) e não algo que preexista a essa interação. Também a coerência deixa de ser vista como mera propriedade ou qualidade do texto, passando a dizer respeito ao modo como os elementos presentes na superfície textual, aliados a todos os elementos do contexto sociocognitivo mobilizados na interlocução, vêm a constituir em virtude de uma construção dos interlocutores, uma configuração veiculadora de sentidos. (itálicos da autora)

Observamos, assim, que a produção de um texto vai além da superfície oral/ escrita, envolvendo, pois, todo um contexto de produção que se refere ao que é dito, a quem é dito, como é dito, onde é dito e com que intenção é dito. Koch \& Elias (2010, p. 59) se referem ao contexto como "Tudo aquilo que, de alguma forma, contribui para ou determina a construção do sentido". Vejamos o que dizem Halliday \& Hasan (1976, p. 30) sobre contextos de situação:

Uma série de configurações semânticas que estão associadas a classes específicas de contextos de situação e que definem a substância do texto: o que ele significa, no sentido mais amplo, incluindo todos os componentes de seu significado social, expressivo, comunicativo, representacional, etc.

Partindo desse contexto, percebemos que o ensino de produção textual com finalidade social é essencial à produção de texto, uma vez que sua configuração depende disso. Sabemos que, infelizmente, grande parte dos textos produzidos na escola não têm essa característica tão importante. São escritos com a finalidade de cumprir um dever escolar. $\mathrm{O}$ aluno faz a redação sobre suas férias, o professor a corrige, devolve a ele, e o próximo passo é o lixo.

A natureza de produções textuais como essa é desinteressante para o aluno, uma vez que ele escreve como pura obrigação, sem motivação; tem o que dizer, mas já disse tantas vezes, qual é a finalidade social? Com que interlocutor está interagindo (acho que o professor nem vai ler essa redação - pensa o aluno)? Com que intenção e/ou objetivo deverá escrever?

Dessa forma, para que a escrita ganhe a dimensão que pretendem os estudiosos da linguística textual e os próprios PCNs, ela precisa obedecer a alguns quesitos. Vale destacar que o que colocamos a seguir não pretende ser uma "receita", mas tão somente o apontamento de questões já constatadas por diversos estudiosos 
na prática de ensino de produção textual, tais como: Koch (1997), Koch \& Elias (2010), Geraldi (1999), Ruiz (2010), Antunes (2010), Cavalcante (2003) e Hayes \& Flower (1980).

No que se refere à produção textual, é preciso:

- Acionar os diversos tipos de conhecimentos necessários à produção de um texto (conhecimento linguístico, conhecimento enciclopédico e conhecimento interacional);

- Estar situada em contexto de uso real (todo o entorno textual);

- Fazer sentido (coerência textual),

- Apresentar os elementos da textualidade (continuidade, progressão, nãocontradição e articulação).

No que se refere às condições de produção é preciso que se estabeleça:

- Uma finalidade social à produção textual dos alunos;

- Frequência e diversidade de gêneros e local da escrita, isto é, a escola não deve ser o único local onde os alunos escrevem.

No que se refere à intervenção do professor, é preciso:

- Detectar os problemas do texto;

- Selecionar metodologias a serem aplicadas com a finalidade de resolver o problema;

- Levar o aluno à refacção desse texto com a finalidade de que este perceba onde estão os problemas na sua escrita.

\section{ANÁLISE DOS DADOS: OS PROBLEMAS MAIS FREQUENTES NO USO DE MECANISMOS DE REFERENCIAÇÃO E PROGRESSÃO TEXTUAL NOS TEXTOS ACADÊMICOS DE ALUNOS DO PARFOR}

\subsection{Na referenciação}

Os estudos feitos no âmbito da Linguística Textual, especificamente no que tange à referenciação - que é uma atividade discursiva estritamente relacionada à 
cognição - já descreveram diversas formas pelas quais são criados, introduzidos e reativados objetos-de-discurso nas produções textuais.

Durante muito tempo, discutiu-se, na linguística, a diferença entre língua falada e língua escrita, apontando-as como dois polos opostos. Hoje, a abordagem mais discutida e aceita entre os estudiosos é aquela que trata as duas modalidades num continuum tipológico, isto é, analisa-as a partir das mesmas condições de produção. Entretanto, é fato que existem diferenças entre as duas modalidades. Assim, há estratégias textuais aplicadas e até bem aceitas na modalidade oral, mas que, se aplicadas à escrita, comprometem o sentido do texto, pois como já se disse, modalidade escrita e modalidade oral têm características próprias, isto é, mesmo que partilhem de vários traços, não são isomórficas. Dessa forma, os alunos devem utilizar-se de outras estratégias. Nesse trabalho, preocupamo-nos exclusivamente com as estratégias de referenciação adotadas especificamente no âmbito da produção escrita.

A introdução de objeto-de-discurso pode dar-se de forma ancorada ou de forma não-ancorada. A introdução de objeto-de-discurso novo tende a ocorrer de forma não ancorada; já a reativação de objetos-de-discurso tende a dar-se de forma ancorada.

A nossa análise apontou que ocorre, nos textos de alunos do PARFOR, a introdução de objetos-de-discurso novos de forma ancorada, isto é, como se já fossem conhecidos dos interlocutores. A seguir, exemplos extraídos de textos desses alunos $^{3}$.

Texto L: Reflexão e eliminação da reprovação nas escolas

(1) "A escola é um lugar de aprendizagem onde as crianças vão buscar conhecimentos onde os saberes aos poucos vão tomando seu lugar na vida dos seres humanos e é neste momento em que pessoas que como nós fazemos um papel muito importante para com a sociedade, nos capacitamos para dar esse suporte de conhecimentos que é nato que cada um trás dentro de si, e cabe ao professor junto a coordenação pedagógica apenas moldar e aprimorar esse conbecimento".

Da mesma forma, percebemos também a reativação de objetos-de-discurso como se fossem novos, isto é, formalmente, aparecem numa roupagem de objeto-de-discurso novo:

(02) "Os alunos chegam ao Ensino Médio e até mesmo na Faculdade sem conhecimento. E outros nem conseguem ingressar [...] A avaliação mediadora vem para contribuir no

3 Os textos foram transcritos aqui tal como se encontram nos originais de seus autores, salvo, os destaques que são nossos. 
processo avaliativo escolar. Por ser um método de acompanhamento está em constante sondagem $[\ldots]^{\prime \prime}$

A anáfora associativa é um recurso largamente utilizado por esses alunos na referenciação. Vejamos alguns dados:

(03) "Uma boa parte do sistema a educacional está preocupado com a quantidade, isto é, a aplicação de investimento nessa área vem muito mais se houver bons resultados de aprovação".

(04) "O governo vem investindo em políticas educacionais visando a melhoria da educação pública. Uma das políticas atuais é a correção de fluxo, uma política que está sendo implantada para diminuir o índice de evasão e reprovação escolar".

(05) "A avaliação, apesar da responsabilidade de nós professores, não deve ser considerada função exclusiva dele. Delegá-la aos alunos em determinados momentos, é uma condição didática necessária para que construam instrumento de auto-regulação para as diferentes aprendizagem".

Percebemos assim que, embora essas estratégias sejam legítimas e amplamente utilizadas na nossa linguagem do dia-a-dia, não constituem estratégias típicas de produções escritas inseridas no gênero acadêmico. Esses dados demonstram uma forte interferência da oralidade na escrita de alunos universitários. Embora não se esperem ocorrências desse tipo em textos desse tipo de aluno, os dados demonstram que eles existem e são bem frequentes. Logo, é necessário traçar contornos que visem a auxiliar esses alunos nessa questão, com a finalidade de fazê-los atingir o nível exigido nos textos de natureza acadêmica.

\subsection{Na progressão textual}

Nossas pesquisas revelaram que o uso de anáfora sem antecedente explícito é um recurso adotado por esses alunos para fazer o texto progredir. Embora constitua uma estratégia legítima e bastante utilizada na linguagem cotidiana, sendo encontra$\mathrm{da}$, inclusive, em textos de circulação em massa, esse recurso leva o interlocutor a mobilizar diversos tipos de conhecimentos e estratégias, como recorrer a elementos co-textuais, conhecimentos enciclopédicos e esquemas cognitivos para tentar compreender o texto, e sempre há o risco de o interlocutor não compreender, como pretendia seu autor. Vejamos os exemplos abaixo: 
(06) "[...] Há uma questão política muito forte por trás de toda essa questão, discursos muito bonitos que engana muita gente sem conhecimento da realidade escolar, porque eu não me engano. Os projetos políticos brasileiros são feitos a curto prazo e não se melhora a educação de uma hora para outra, como eles dizem que a educação está no rumo certo $[\ldots]^{\prime \prime}$.

(07) "O aluno em sala de aula deve estar informado de maneira qualitativa e de maneira diferente das que ele já viu sobre o que aprender o que eles precisam saber fazer melhor procurar fazer correções e comentários sobre as produções de textos do aluno. Neste momento, procurar oferecer indicações claras para que possam melhorar seu aprendizado".

Através do contexto, podemos depreender que o pronome eles em (06) não faz referência a um antecedente explícito, mas a um referente extratextual. Através do co-texto, recorrendo ao nosso conhecimento de mundo, é possível inferirmos que o referente do pronome eles é político. Essa inferência é possível porque através de nossos conhecimentos de mundo e conhecimentos enciclopédicos, sabemos que esse é o discurso atual dos políticos para a educação.

Em (07), o pronome eles, de imediato, parece se referir a um antecedente explícito: aluno, expresso anteriormente pelo pronome ele, o que seria uma retomada anafórica sem os atributos do antecedente. Na continuidade da leitura, percebemos que o pronome se refere a professores. Isso é possível porque fazemos inferências baseadas em nosso conhecimento de mundo sobre como o professor ensina ou deve ensinar e o que é função do professor. Além disso, a estrutura da língua auxilia na identificação da função do termo aluno. No nível sentencial, esse termo é parte do objeto produção de textos de alunos da oração em que o referente professores não está explícito e é retomado pelo pronome anafórico eles, cuja função gramatical desempenhada no interior da sentença é a de sujeito. Neste caso, essa retomada anafórica, sem antecedente explícito, exige muita cooperação por parte do interlocutor para construir o sentido do texto. Sem essa cooperação, intencionalmente ou não, estaríamos diante de um texto opaco.

Diante dessas duas situações, podemos dizer que a explicitude da referência pode apresentar graus variados de dificuldades, indo de uma referência que é explicita, direta no texto, passando por uma referência sem antecedente explícito, mas cuja dificuldade é pequena para a identificação do referente, e, finalmente, alcançar a referência que apresenta nível maior de dificuldade, levando o interlocutor a fazer diversas operações cognitivas para chegar ao referente.

Em textos como os apresentados atrás, há opacidade que dificulta sua compreensão. Segundo Dascal e Weizman (1987, p. 6), um texto pode apresentar-se 
opaco pela incompletude proveniente da dificuldade do leitor em atribuir sentido ao que lê, por faltarem dados tanto no contexto como co-texto para completar lacuna(s); ou pela crença, por parte do leitor, de que a informação veiculada pelo texto não é necessariamente aquela pretendida pelo seu produtor.

A ocorrência desses problemas está relacionada aos vários fatores cognitivos envolvidos na compreensão/produção de texto. Segundo Koch (1997), esses fatores são de caráter linguístico, de caráter enciclopédico e de caráter interacional.

A reiteração é outra estratégia bastante utilizada para fazer o texto progredir, conforme podemos observar nos exemplos abaixo:

(08) "[...] A progressão automática pode-se colocar a escola num patamar de desvalorização do ensino e como tudo pode a escola passa a ser vista como uma passagem e não um lugar de aprendizagem, de busca, de mediação entre docentes e discentes.

A progressão automática pode causar sérias consequências para o aluno no futuro, ele ser aprovado para uma série que não atende as habilidades básicas para desenvolver seus estudos, vai estar atrofiado, sentindo despreparado para avançar em seus estudos".

(09) "A escola é uma instituição democrática onde se prepara cidadãos competentes para ocupar um lugar no mercado de trabalho. Isso porém, depende do compromisso em que cada escola desempenha com a educação de seus alunos".

Sabe-se que esse tipo de estratégia, embora utilizado no gênero escrito, e tenha muitas vezes um forte teor retórico, é uma característica do texto oral, seu uso no gênero acadêmico deve, portanto, ser cuidadoso.

\section{ESTRATÉGIAS QUE PODEM SER ADOTADAS NO ENSINO DA PRODUÇÃO TEX- TUAL PARA AUXILIAR O USO DE REFERENCIAÇÃO E PROGRESSÃO TEXTUAL}

Concordamos com Marcuschi (2008. P. 81), segundo o qual "Todos temos uma competência textual-discursiva relativamente bem desenvolvida, não há o que ensinar propriamente. Nosso papel, neste momento, é compreender como isto funciona e como podemos fazer com que funcione ainda melhor". É, pois interesse deste trabalho verificar como podemos intervir na produção textual do grupo de alunos acima citado, no sentido de levá-los a produzir textos transparentes, fazendo com que desempenhem melhor sua competência textual.

Sabe-se que o domínio de estratégias de qualquer gênero discursivo implica, logicamente, no conhecimento do referido gênero que, por sua vez, implica contato com ele. Vimos, anteriormente, que o sujeito aqui implicado foi fruto de um ensino 
voltado para regras gramaticais, um sujeito, que pela sua trajetória, não foi exposto suficientemente ao gênero acadêmico, de forma que não domina todas as técnicas/ formas necessárias ao bom desempenho desse tipo de gênero. Neste trabalho adotamos a concepção de gênero do discurso de Bakhtin (1992, p. 279), segundo a qual:
A utilização da língua efetua-se em forma de enunciados (orais e escritos), concretos e únicos, que emanam dos integrantes duma ou doutra esfera da atividade humana. O enunciado reflete as condições específicas e as finalidades de cada uma dessas esferas, não só por seu conteúdo (temático) e por seu estilo verbal, ou seja, pela seleção operada nos recursos da língua - recur- sos lexicais, fraseológicos e gramaticais - mas também, e, sobretudo, por sua construção com- posicional. [...] cada esfera de utilização da língua elabora seus tipos relativamente estáveis de enunciados, sendo isso que denominamos gêneros do discurso.

Pensamos que, se partirmos dos pontos em que os alunos apresentam dificuldades, desenvolvendo atividades, levando-os a compreenderem sua escrita e o que se espera dela, poderemos levá-los a ampliar sua competência textual, fazendo-a funcionar melhor, isto é, levá-los a produzir textos coesos, cuja explicitude não demande tanto esforço de compreensão por parte do leitor.

Uma sequencia didática ${ }^{4} \mathrm{com}$ atividades como as que seguem poderia ajudar esses alunos a superarem a dificuldade com pontos da referenciação e da progressão textual:

a) Levar os alunos a conhecerem suas falhas no que tange à referenciação e progressão textual. O objetivo é fazer com que visualizem outras possibilidades de dizer o que é dito, isto é, mostrar que existem formas mais apropriadas disponíveis para expressar aquele conteúdo;

b) Comparar as construções dos alunos a outras do mesmo gênero. A finalidade, aqui, é levá-los a apreenderem as características do gênero;

c) Levar os alunos a desenvolverem um conjunto de leituras, atentando para as formas de referir e fazer progredir um texto. O objetivo, aqui, é fazer com que aprendam na prática e possam extrair os conceitos de referenciação e progressão textual e

d) Produzir resenhas a partir dos textos lidos anteriormente, aplicando os conceitos de referenciação e progressão textual.

4 Conforme Dolz, Noverraz e Schneuwly (2004, p. 96), uma sequência didática é um "Conjunto de atividades escolares organizadas, de maneira sistemática, em torno de um gênero textual oral ou escrito". 
Essas sugestões não pretendem ser uma receita para o ensino de referenciação e progressão textual, mas tão somente um ponto de partida, algo que desperte para a necessidade de reflexão sobre as estratégias que esses alunos estão usando e outras de que eles poderiam se apropriar, sendo estas últimas mais adequadas para o gênero acadêmico.

Acreditamos nesta proposta, pois estamos lidando com professores, profissionais formadores de novos profissionais e, se conseguirmos fazer com que compreendam a natureza de suas produções escritas, ampliem os domínios da escrita, certamente isso será repassado a seus alunos que, consequentemente, produzirão textos mais transparentes, desenvolvendo ainda mais sua competência textual e contribuindo para o crescimento da educação no que se refere ao ensino-aprendizagem de língua materna.

\section{CONSIDERAÇÕES FINAIS}

Neste trabalho, procuramos fazer uma reflexão sobre a formação de professores de língua portuguesa, alunos do PARFOR. O nosso ponto de partida foram suas produções escritas no gênero acadêmico, especificamente a parte que diz respeito à referenciação e à progressão textual.

No percurso que fizemos, ficou evidenciado que esses professores são fruto de uma educação de cunho behaviorista e a técnica de gramática tradicional foi a que prevaleceu ao longo de seus anos de estudos. É possível que o uso pouco frequente da escrita de gênero acadêmico tenha contribuído para falhas em suas escritas, sendo em vários momentos constatadas fortes influências de características predominantemente orais, como estratégias de referenciação e progressão textual.

A descrição do contexto escolar a que estiveram expostos esses alunos não é uma tentativa de justificar suas atividades, mas de refletir sobre o fato, a fim de que possam ser traçadas metas para amenizar a situação, uma vez que, como já se disse atrás, são profissionais formadores de outros profissionais e, se o problema não for solucionado na base, continuará a se estender e atingir seus formandos.

\section{REFERÊNCIAS BIBLIOGRÁFICAS}

APOTHÉLOZ, D. \& REICHLER-BEGUELIN. (1995). Construction de la réference et strategies designation. In: Berrendonner \& Reichler-Beguelin (Eds.). Du sintagme nominal aux objets-de-discours. Neuchâtel: Université de Neuchâtel, p. 227-271. 
APOTHÉLOZ, D. (2003). Papel e funcionamento da anáfora na dinâmica textual. In: Cavalcante, M; Rodrigues, B. B.; Ciulla, A. (Orgs.) Referenciação. São Paulo: Contexto, p. 53-84.

ANTUNES, I. (2010). Aula de Português: encontro \& interação. Parábola Editorial. São Paulo.

BAKHTIN, M. (1992). Estética da Criação Verbal. São Paulo: Martins Fontes.

BAKHTIN, M. (1986). Marxismo e filosofia da linguagem: problemas fundamentais do método sociológico na ciência da linguagem. São Paulo: Hucitec.

BEAUGRANDE, R. (1997). New Foundations for a Science of Text and Discourse: Cognition, Communication, and the Freedom of Access to Knowledge of Society. Norwood, New jersey, Ablex.

BRASIL. (1998). Secretaria de Educação Fundamental. Parâmetros Curriculares Nacionais: Terceiro e quarto ciclos do ensino fundamental: lingua portuguesa. Brasília: MEC/ SEF.

CAVALCANTE, M. M. (2003). Expressões referenciais - uma proposta classificatória. In: Cadernos de Estudos Linguísticos, 44, Campinas, IEL/Unicamp, pp. 105-118.

DASCAL, M. \& WEIZMAN, E. (1987). Contextual exploitation of interpretation clues in text understanding: an integrated model. In: Verschueren, J. \& M. Bertucelli-Papi (eds.). The pragmatic perspective. Amsterdam: Benjamins, pp. 31-46.

DOLZ, J.; NOVERRZ, M.; SCHNEUWLY, B. (2004). Sequências didáticas para o oral e a escrita: apresentação de um procedimento. In: Gêneros orais e escritos na escola. Campinas: Mercado das Letras, p. 95-128.

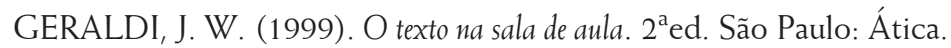

HALLIDAY, M. A. K.\& HASAN, R. (1976). Cobesion in spoken and written english. Londres: Longman.

HAYES, J. \& FLOWER, L. (1980). Identifying the organization of writing processes. In Gregg, L; Steinberg, E. (eds.) Cognitive processes in writing: An interdisciplinary approach. In New Jersey: Lawrence Erlbaum.

KLEIMAN, A. B. (org.) (1995). Os significados do letramento. Campinas: Mercado de Letras.

KLEIMAN, A. B. (1993). Oficina de leitura. Campinas: Pontes/Unicamp.

KLEIMAN, A. B. (1989). Texto e leitor. Campinas: Pontes/Unicamp.

KOCH, I. V. (2006). Léxico e progressão referencial. In: Rio-Torto, Graça.; Silva, Fátima; Figueiredo, Olívia (Orgs.). Estudos em bomenagem ao Professor Doutor Mário Vilela. 1. ed. Porto: Faculdade de Letras da Universidade do Porto. pp. 263-276.

KOCH, I. V. (2005). Introdução à linguística textual. São Paulo: Martins Fontes.

KOCH, I. V. (2002). Linguagem e cognição: a construção e reconstrução de objetos-de-discurso. Em Veredas - revista de estudos linguísticos, v.6, n.1, pp. 29-42. Juiz de Fora: Ufjf.

KOCH, I. V. (1997). O texto e a construção de sentidos. São Paulo: Contexto.

KOCH, I. V. (1992). A inter-ação pela linguagem. São Paulo: Contexto.

KOCH, I. G. V. \& ELIAS, V. M. (2010). Ler e escrever: estratégias de produção textual. 2a . Ed., Contexto, São Paulo. 
KOCH, I. G. V. \& ELIAS, V. M. (2009). Ler e compreender: estratégias de produção textual. $3^{\mathrm{a}}$. Ed. São Paulo: Editora Contexto.

KOCH, I. G. V \& MARCUSCHI. L. A. (1998). Processos de referenciação na produção discursiva. DELTA, v.14, nº Especial, pp.169-190.

MARCUSHI, L. A. (2001). Anáfora indireta: o barco textual e suas âncoras. Editora da UFPR, Revista Letras, Curitiba, n. 56, pp. 217-258.

MARCUSHI, L. A. (2008). Produção textual, análise de gênero e compreensão. Parábolas. MATÊNCIO, M. L. M. (2006). Letramento na formação do professor - Integração e Práticas Discursivas e Construção da Identidade Profissional. In: Corrêa, M. Ensino de lingua: representação e letramento. Campinas: Mercado de Letras.

MONDADA, L. (1994). Verbalization de léspace et fabrication du savoir: approcbe linguistique de la construction des objets $d u$ discours. Lausanne: Université de Lausanne.

MONDADA, L. \& DUBOIS, D. (1995). Construction des objets de discours et catégorisation: une approche dês processus de référentiation. In: Berrendonner \& Reichlerneves, M.H. Du sintagme nominal aux objets-de-discours. Neuchâtel, Université de Neuchâtel 1995, pp. 273-305.

POSSENTI, S. (1996). Por que (não) ensinar gramática na escola. Campinas, S.P. ALB (Associação de Leitura do Brasil). Mercado de Letras.

ROJO, R. H. R. (2005). Os PCNs, as práticas de linguagem (dentro e fora da sala de aula) e a formação de professores- uma representação. In: Rojo, R. H. R. A Prática de linguagem em sala de aula: praticando os PCNs. Mercado de Letras, Campinas.

ROJO, R. H. R. (1996). Perspectivas enunciativo-discursivas em produção de textos. Anais do VI Congresso Brasileiro de Linguística Aplicada. Campinas: DLA/IEL/Unicamp.

ROJO, R. H. R. (1989). O desenvolvimento da narrativa escrita: fazer pão e encaixar. Tese de doutoramento. São Paulo: PUC-SP.

RUIZ, E. D. (2010). Como se corrige redação na escola. São Paulo, Editora Contexto.

SOARES, M. (1996). Português na escola: história de uma disciplina curricular. Revista de Educação AEC, n. 101. Campinas: IEL/Unicamp.

SOARES, M. (1986). Linguagem e escola: uma perspectiva social. 2. ed. São Paulo: Ática, 1986.

TEBEROSKY, A. (1994). Aprendendo a escrever. São Paulo: Ática.

TEBEROSKY, A. \& CARDOSO, B. (org.) (1989). Reflexões sobre o ensino da leitura e da escrita. São Paulo: Trajetória/Unicamp.

VAN DIJK, T. A. \& KINTSCH, W. (1983). Strategies of discourse comprebension. San Diego, Academic Press, Inc.

Recebido: 22/08/2013

Aceito: 06/04/2014 